\title{
AN INNOVATIVE SHELL STRUCTURE IN CODOGNO (ITALY) EVALUATION OF STRUCTURAL AND SEISMIC PERFORMANCE
}

\section{PIERANGELO BRUGNERA ${ }^{1}$, M. GRAZIA COSTA ${ }^{1}$, GIULIO MIRABELLA-ROBERTI ${ }^{2 *}$}

\author{
${ }^{1}$ SACEE s.r.l. - Dept. Structural Design (DPS) \\ piazza Luigi di Savoia, 22 - 20124 Milano (MI), Italy \\ e-mail: \{pierangelo.brugnera, grazia.costa\}@ sacee.it - https://www.sacee.it \\ ${ }^{2}$ Dept. of Engineering and Applied Sciences (DISA), University of Bergamo \\ viale Marconi, 5 - 24040 Dalmine (BG), Italy \\ e-mail: giulio.mirabella@unibg.it - https://disa.unibg.it (*corresponding author)
}

Keywords: Hypar, saddle shaped shell, structural assessment, prefabrication

\begin{abstract}
The saddle-shaped shells, or hyperbolic paraboloids, often joined together to form a pitched roof or an inverted umbrella, were used by many pioneers in structural architecture, such as Félix Candela, which introduced a very innovative use of reinforced concrete in thin layers or together with some reticulated ribs.

An innovative semi-prefabricated building system was developed in Italy in the years '30 of $X X$ cent by a very active brick factory near Piacenza, RDB: the SAP system, that allowed building curved surfaces by prefabricating light elements. After WW2, this technique was applied also for the new structures covering wide spaces for the developing industry or also for public leisure, using prefabricated panels of the desired length. A particularly interesting application was the BISAP (double-SAP) panel that could be adapted for building large shells.

In Codogno (LO), Italy, the BISAP panels were employed to cover a large sports hall, spanning about $37 \times 26 \mathrm{~m}$, without intermediate supports, resting (mainly) on the four corner pillars. Border pitch beams sustain at the top two crossed beams that separate (and support) the four hypar fields. On the four sides, two rafter beams are connected by horizontal prestressed tie beams, in order to minimize displacements and assure the preservation of the original shape.

The first aim of the structural analysis was to assess the static conditions of the roof under the service loads assigned by Italian code for SLS, and then to evaluate seismic vulnerability at ULS of the whole sports hall, being a public space subjected to particular safety provisions. The FE code used (Straus7) allowed a very careful discretization of the orthotropic slab with the correct inclination and twist of the ribs, giving a reliable forecast of the behavior also in seismic conditions: the dynamic analysis of the modal shapes gives a satisfactory response of the shell, which maintains nearly unchanged his shape during free vibration modes. The seismic safety of the structure can be then increased by simply augmenting the stiffness of the four corner supports, where shear action is concentrated, by adding ribs to the L-shaped sections to form cross shaped ones. In this way also the slenderness (and weakness) of additional intermediated pillars could be overcome.
\end{abstract}




\section{INTRODUCTION}

In September 2018, the Municipality of Codogno charged SACEE s.r.l. to study a solution for improving the usage of the sport-hall, a public property built in 1975 as an annex to the secondary school, but over time more and more exploited as public space for sports events.

Some of the problems regarded the compliance to the codes for fire protection and for accessibility of disabled persons; moreover, a reorganization of accessory spaces was requested. A more general problem concerneded the thermal and lighting comfort improvement, both for a better energetic behaviour and economic savings. In the meantime, the safety assessment of the structure was requested, in order to forecast the impact of the needed strengthening interventions.

The main building of the Codogno Sports Hall (see Fig. 1) is about $37 \times 26$ m wide, with no intermediate supports, resting (mainly) on the four corner pillars. Border pitch beams, forming four triangular tympana, sustains at the top two crossed beams that separate (and support) the four hypar fields. On each side, the two rafter beams are connected horizontally by prestressed tie beams, in order to minimize displacements and assure the preservation of the original shape. Some low-rise buildings, used as changing and service rooms, are contiguous to the main building on two sides but supported by indipendent structural systems.

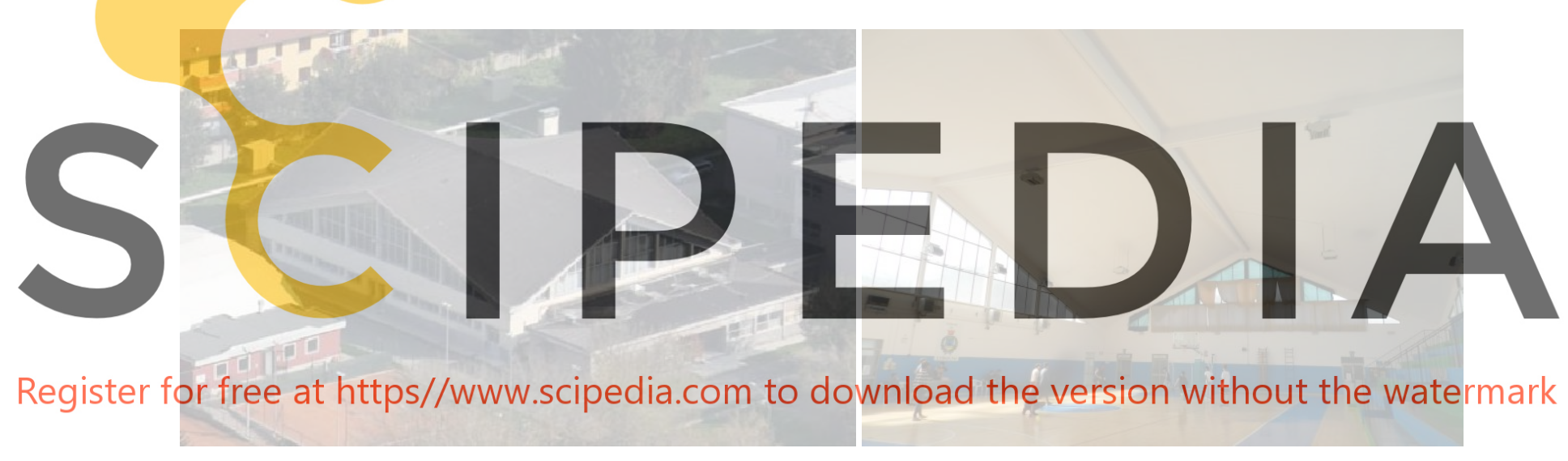

Figure 1. The Codogno sport hall: aerial view (left) and the interior (right).

\section{SUCCESS AND DECLINE OF THE HYPAR SHELLS}

The shape of Codogno Sports Hall roof belongs to the family of surfaces composed by hyperbolic paraboloids, which were used by many pioneers in structural architecture after WW II, such as Félix Candela in Mexico, Arata Isozaky in Tokyo, P.L. Nervi and P. Belluschi in St. Francisco [1]. Very expressive architectural forms were obtained combining simpler geometrical shapes, with a very innovative use of reinforced concrete in thin layers or with some reticulated ribs.

In a suitable coordinate system, a hyperbolic paraboloid can be represented by the equation

$$
\frac{x^{2}}{a^{2}}-\frac{y^{2}}{b^{2}}=z
$$

In this system, the traces (or cross-sections) parallel to the $x z$ - and $y z$-planes are parabolas and the level curves (traces parallel to the $x y$-plane) are hyperbolas (see fig. 2). The traces open downward along the $x$-axis and upward along the $y$-axis. 

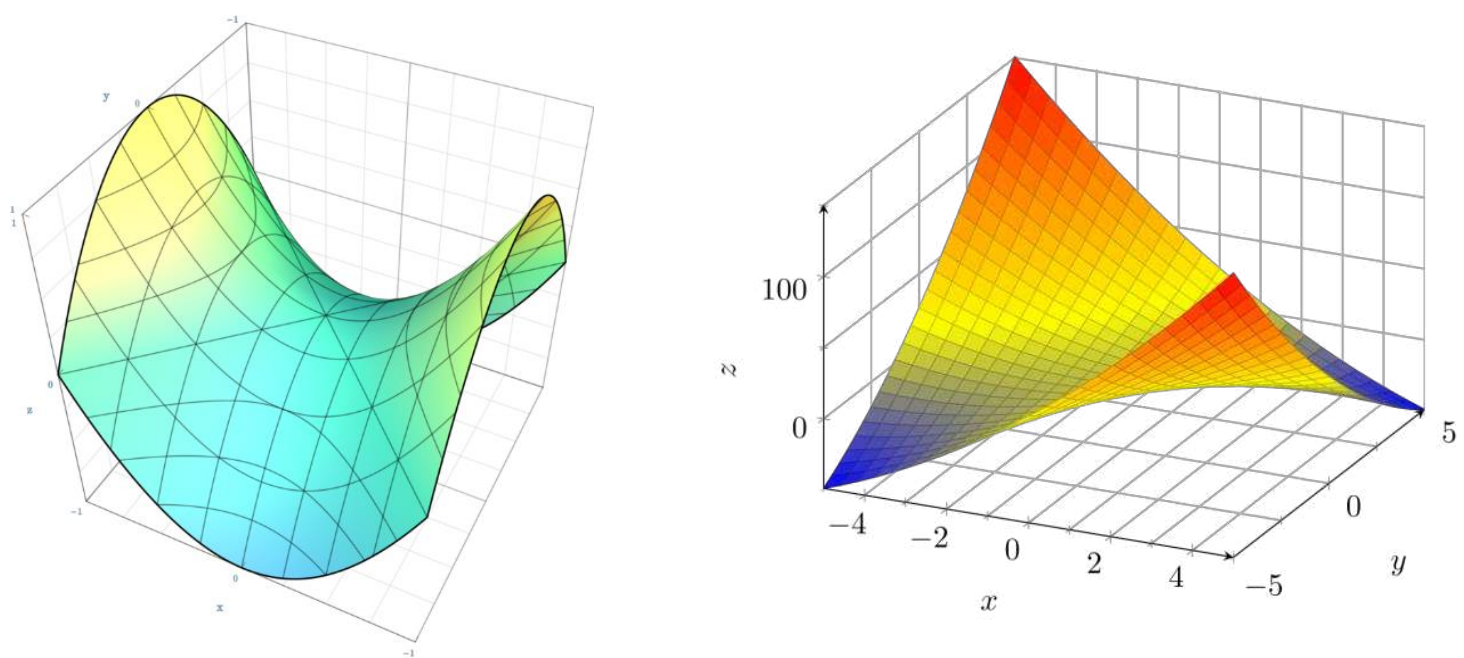

Figure 2: The surface of a hyperbolic paraboloid with $a=b=1$ (on the left) and rotating axis's as in Eq. 2.

Rotating the reference system by $45^{\circ}$ and putting $a=b=\sqrt{2}$ it is possible to represent the surface (1) also with the equation:

$$
z=x y
$$

Moreover, the hyperbolic paraboloid is also a doubly ruled surface: it contains two families

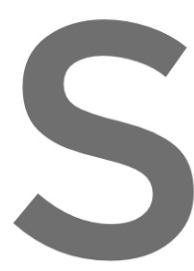
of mutually skew lines. The lines other. A hyperbolic paraboloid is point. Therefore it is no es in each family
is a saddle surf
lopable, despite
ibly ruled means
as formwork: th are parallel to
ace, so its Gaus
being a ruled s
that they are easy
hat explain the a common plane, but
s curvature is negat
surface. Never less,
asy to construct using
success of this sh dut not to each
ative at every
the fact that
shape in the experimental development of 'structural architecture', relying on the innovative usage of castRegister in-place concrete for the construction of thin shells.

Register forfree at https / Ww w. scipedia. com to download the version without the watermark was introduced first by the architect Heinrich Engel in his 1968 book Structure Systems [2].

Fernand Aimond (1902-1984) can be considered as the father of the thin hypar concrete shells, who also formulated the membrane theory of the hypar. He designed and constructed several hypar roofs in France in the 1930s for aircraft hangars and workshops.

However, a master of hypars and joined hypars was a Spanish architect, engineer, structural artist and builder Felix Candela (1910-1997), who popularized the use of hypars for reinforced concrete construction [3]. Candela was influenced by Aimond but followed also the fundamentals of the Eduardo Torroja's work, a famous Spanish structural engineer renowned for his development of thin concrete shell structures.

He designed and built many innovative thin shell concrete roof structures. Most of these structures were built in Mexico in the 1950s and 60s. That was the 'golden era' for thin shell construction. Candela constructed over 300 shells during these decades. His thin concrete vaulted shells were made of reinforced concrete mixed and poured in situ, over wooden formwork. The thin shell roofs allowed the minimum thickness of concrete while having great strength and stiffness at the same time. In 1952 Candela started experimenting with the umbrella structures of four identical quadrants, called tympani. The shell geometry was created 
by joining four straight-edged hypars whose sides rose upwards away from the central column (as if an umbrella blown upward).
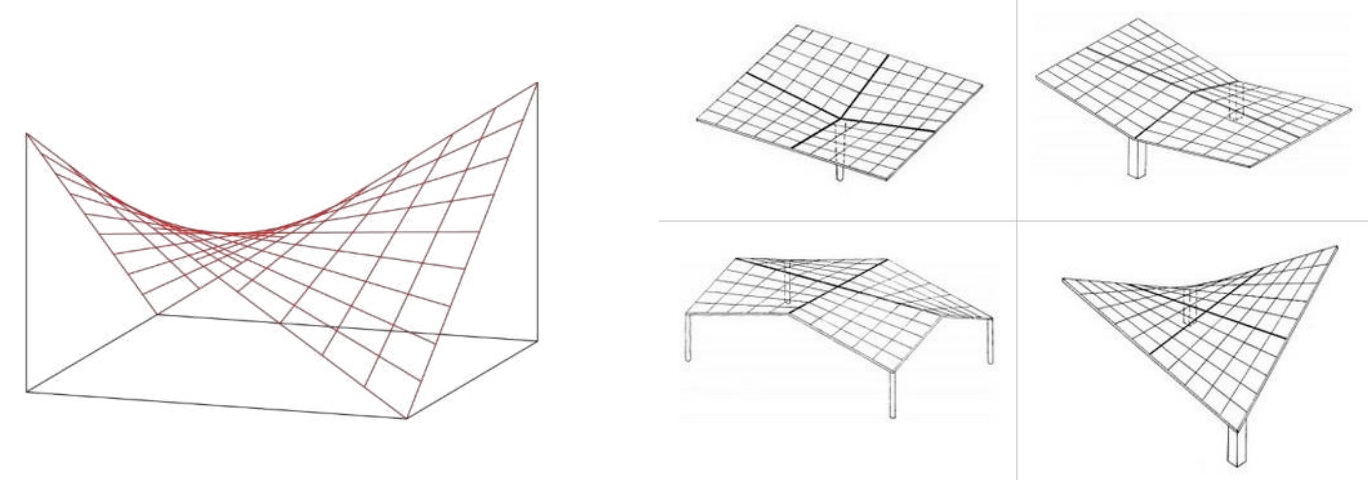

Figure 2. The hypar as ruled surface and four different hypar combinations.

One of his major works is the Lomas de Cuernavaca Chapel ("hills of Cuernavaca"), Mexico, built in 1958. Candela used a single hypar surface to get an open-air chapel with a pure structural form of high impact. The Cuernavaca Chapel shell is self-supporting with a span of $30 \mathrm{~m}$ and dramatic curvature. The open end of the chapel rise to a height of $24 \mathrm{~m}$ (Fig. 3).
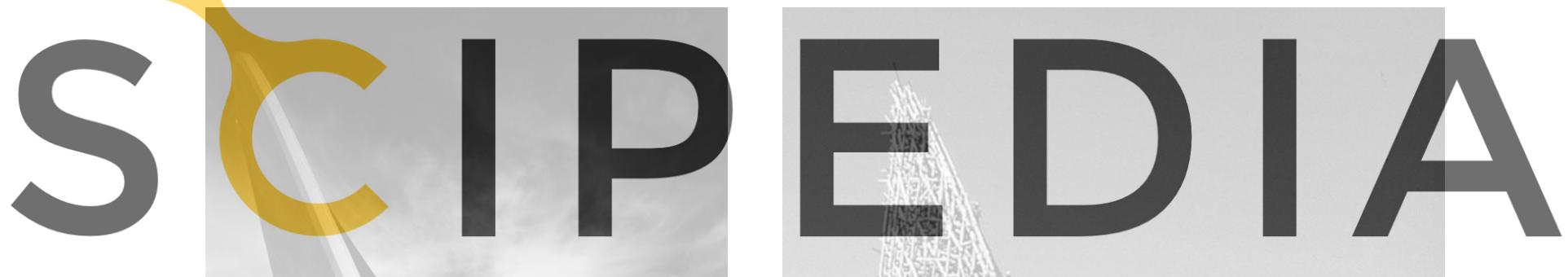

Register for free at https//www.scipedia.com to download the version without the watermark
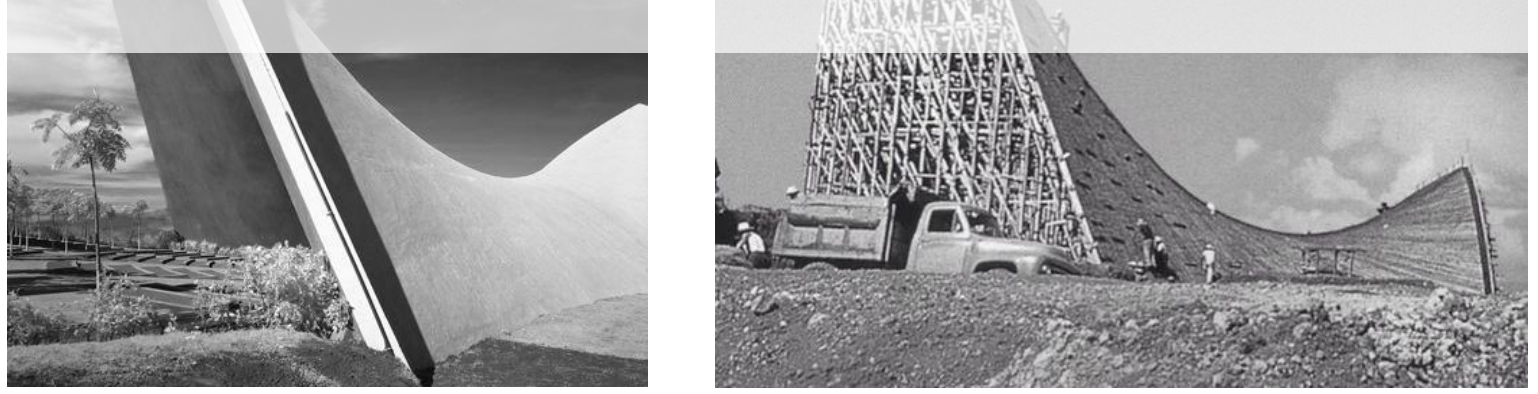

Figure 3. The Cuernavaca chapel finished and under construction.

In 1958, Candela completed also his most significant work, the Los Manantiales Restaurant in Xochimilco, near Mexico City. The Xochimilco shell is composed of four intersecting hypars with free curved edges [4]. The soaring shape at the edges resulted in a simple and gracefully thin shell structure. In the original drawings (Fig. 4), Candela clearly shows the form of Manantiales Restaurant shell. It is an eight-sided groin vault composed of four hyperbolic paraboloid saddles that intersect at the center point. The form was original and unexplored at 
that time. The innovative use of $\mathrm{V}$-shaped beams allows edges free of stiffening beams and produced a shell thickness of only $4 \mathrm{~cm}$.
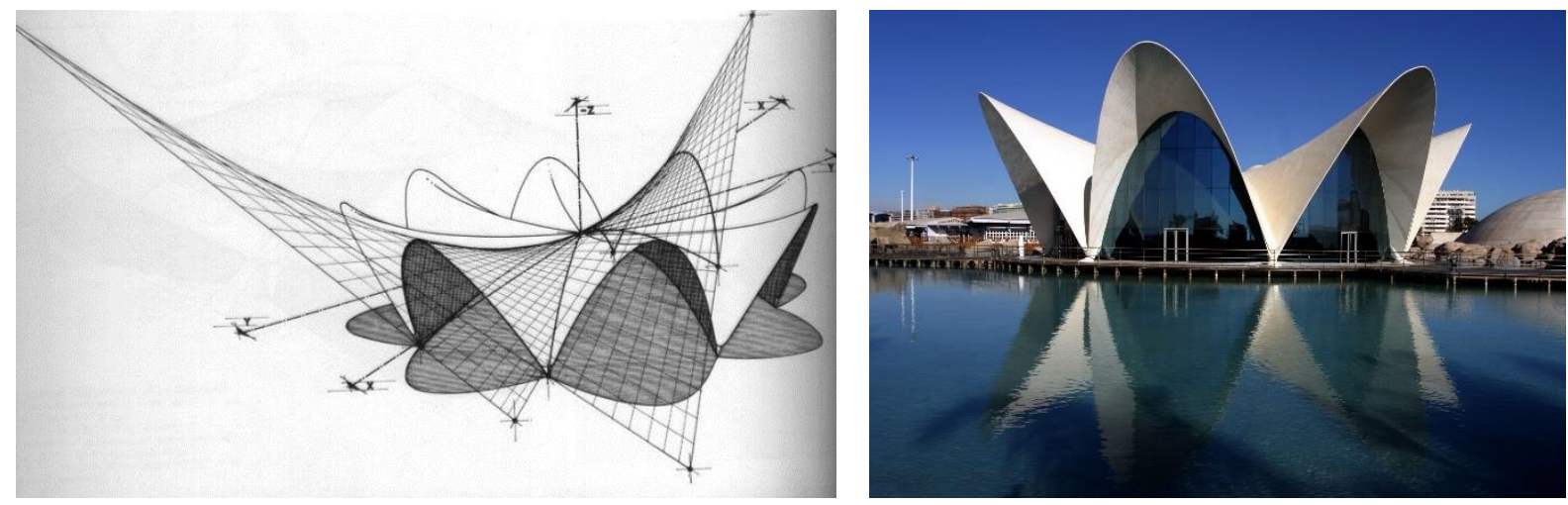

Figure 4. The sketch of the Mantianales (Mexico, 1958) and one of the last works of Candela, the Oceanographic park in Valencia (Spain, 1994) on the same shape.

\section{THE RDB FACTORY AND THE BI-SAP SYSTEM}

\subsection{Starting from a brick kiln near Piacenza}
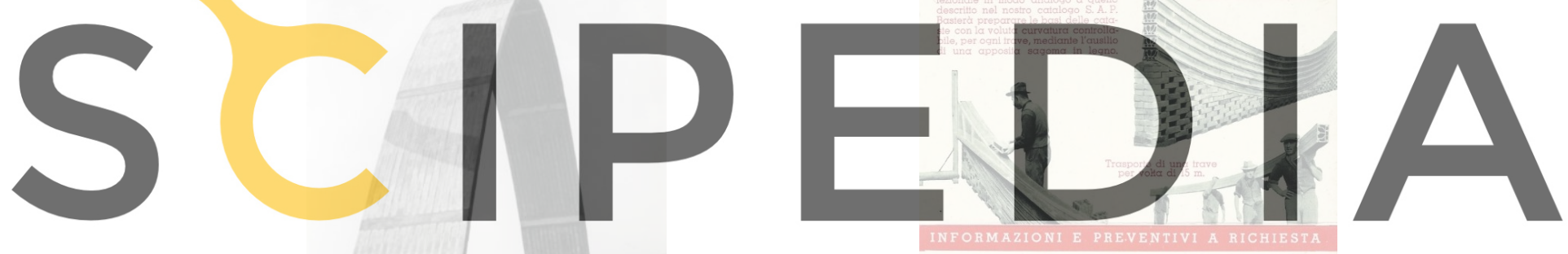

Register for free at https//www.scipedia.com to download the version without the watermark
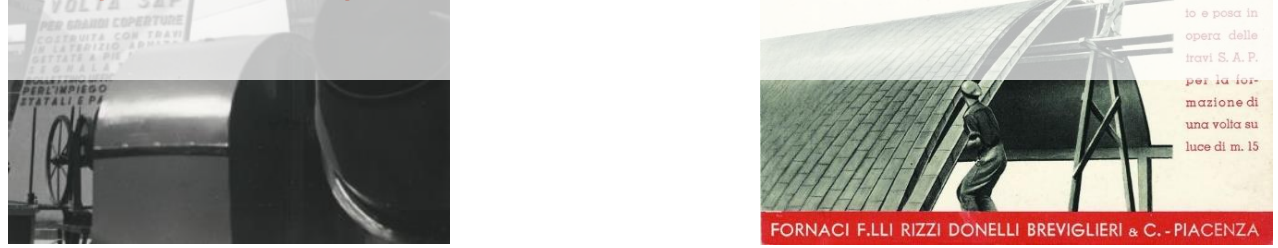

Figure 5. The vault built at Milan Fair in 1938 and a leaflet of SAP vault system.

A very innovative firm in the field of brick production developed between the two WW in the surroundings of Piacenza, in northern Italy. Starting from a brick and lime kiln acquired in 1908, the new firm was established in 1934 as 'Fornaci F.lli Rizzi, Donelli, Breviglieri \& C.' that in 1970 became simply RDB s.p.a. The firm introduced a semi-prefabricated floor system that simplified the erection of civil buildings, but also allowed the construction of large span roof for industrial and leisure settlements. In the Milano fair of 1938 a great vault in 'reinforced bricks' built by RDB shown the possibility offered by the new SAP system (the Italian acronym stands for 'Senza Armatura Provvisoria', that is 'without provisional centring'). Other innovative product were then developed, such as prestressed floor panels, precast and prestressed concrete beams, and so on. 


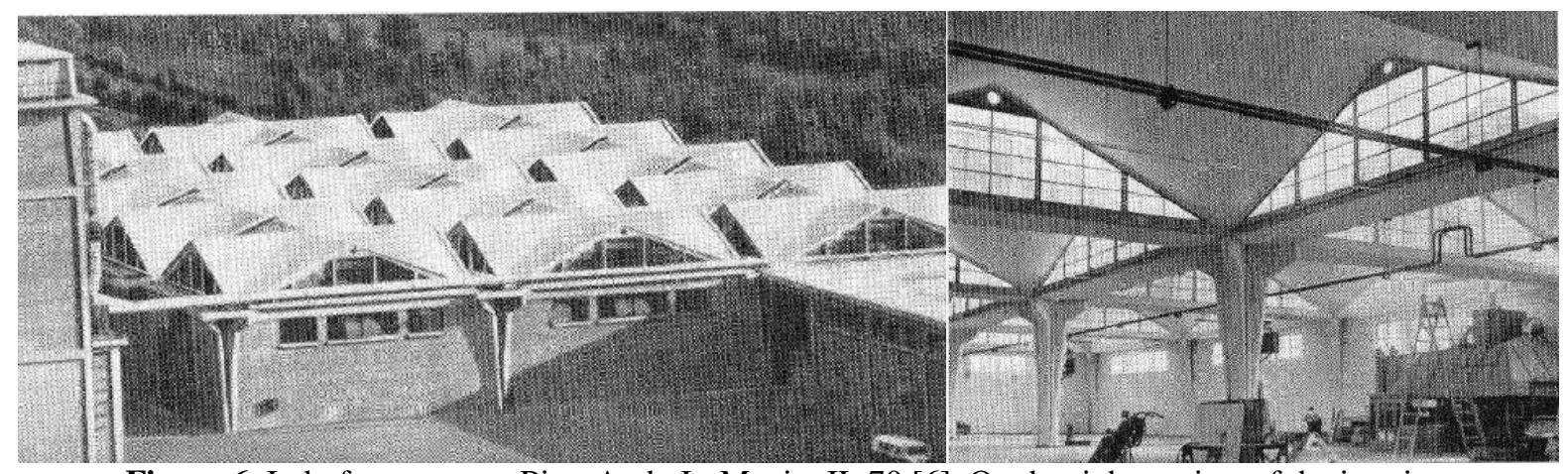

Figure 6. Italp factory, near Pisa. Arch. L. Muzio. IL 70 [6]. On the right, a view of the interior.

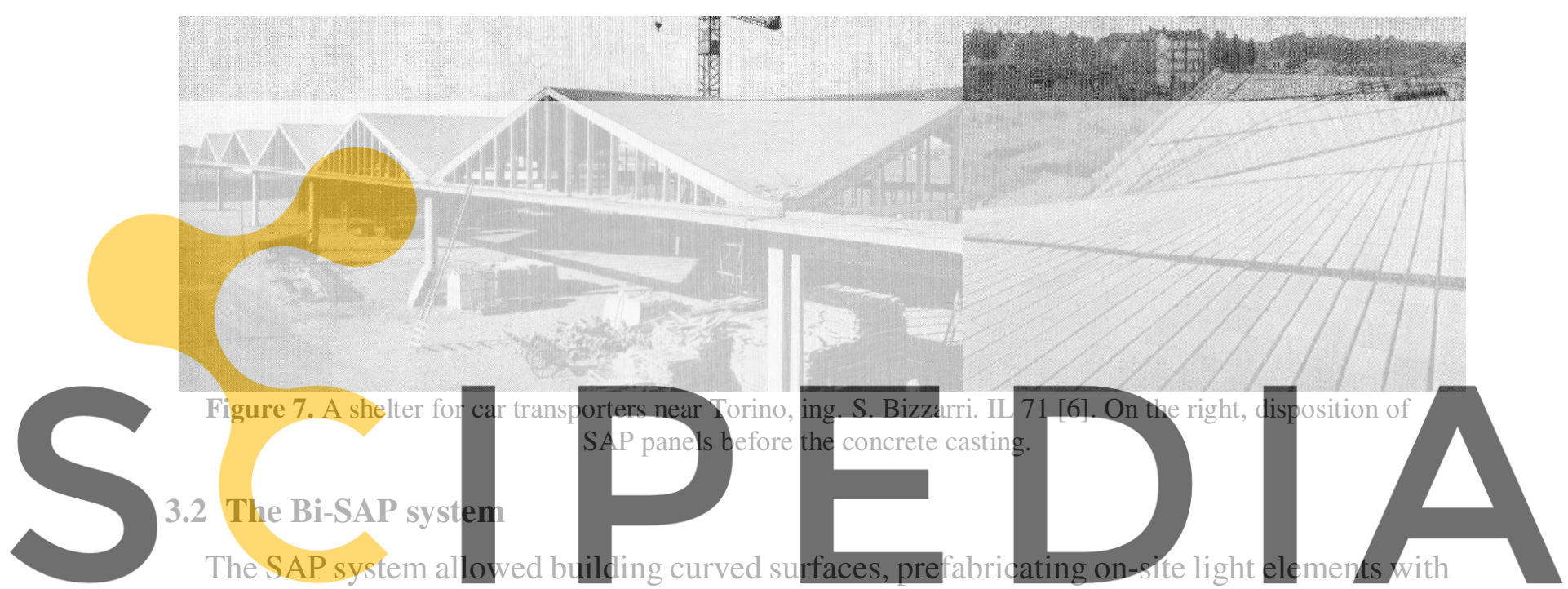

curved shape. After second WW, this technique was applied also for building the new structures

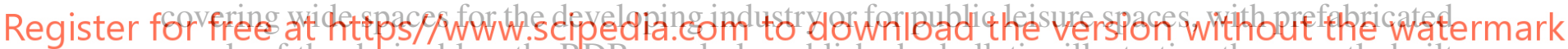

panels of the desired length. RDB regularly published a bulletin, illustrating the recently built

and under construction industrial sheds adopting patented RDB products (Fig. 7), but also

giving useful suggestions for the design and verification of such structures.

A particularly interesting application of the SAP system is the BI-SAP (double-SAP) panel that could be adopted for building large shells generated from ruled surfaces. In this way, hypar shells could be built using lightly skewed panels, prefabricated on site, posed along the straight lines forming the hypar surface.

\section{THE SPORTS HALL IN CODOGNO}

In Codogno (LO), Italy, the BISAP panels were employed to cover a large sports hall built in 1974 , about $37 \times 26 \mathrm{~m}$ wide, without intermediate supports, resting (mainly) on the four corner pillars. The border pitch beams sustains at the top two crossed beams that separate (and support) the four hypar fields. On each side, the two rafter beams are connected horizontally by prestressed tie beams, in order to minimize displacements and assure the preservation of the original shape.

The prefabricated panels, disposed following the rules generating the hypar surface, form these four fields (Fig. 8). Additional reinforcement is disposed orthogonally and at $45^{\circ}$ to the 
rib direction in the concrete slab (fig. 9). Probably for lack of confidence with the structural solution adopted, beside the two big crossing beams separating the four hypar fields, some additional slender pillars supporting the border rafters are disposed on the four sides between the main corner pillars, apparently used only for windows support, but designed to collaborate to the bearing system.
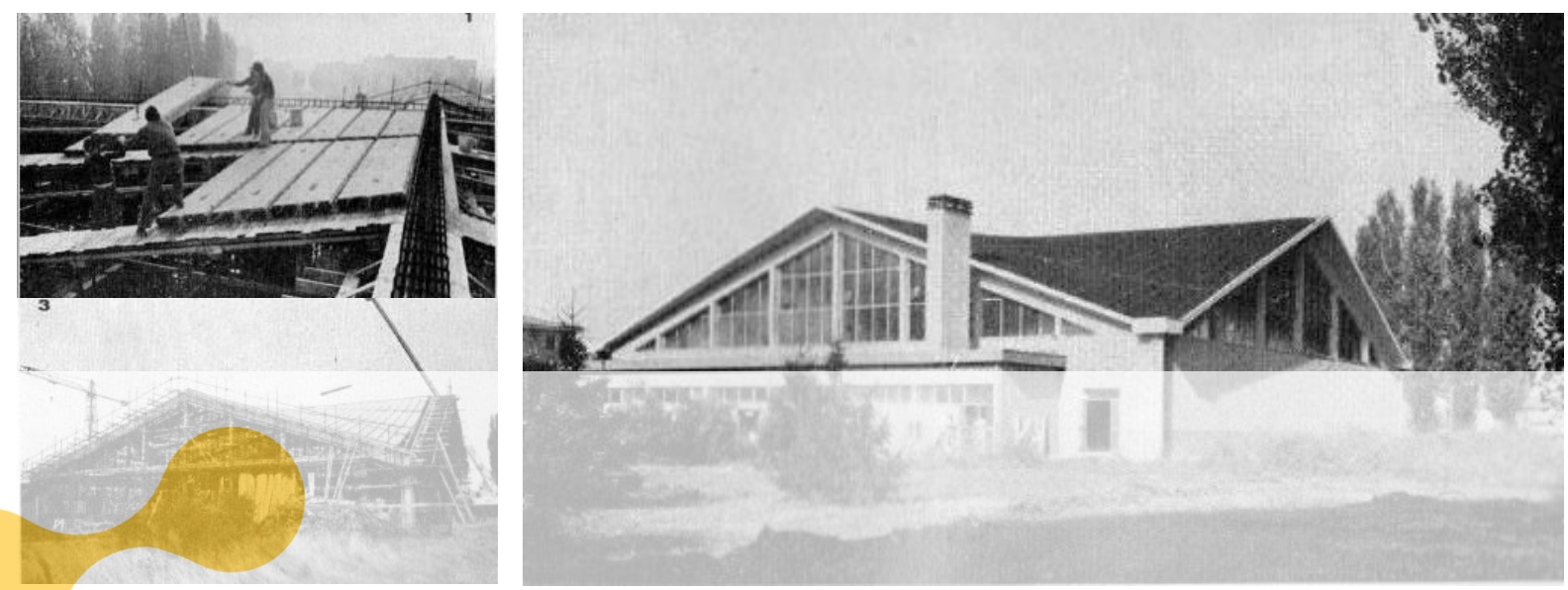

Figure 8. The construction of Codogno Sports Hall and its final appearance. IL 158-159 [7], p.1232.

4.1 Historicall documents and original design
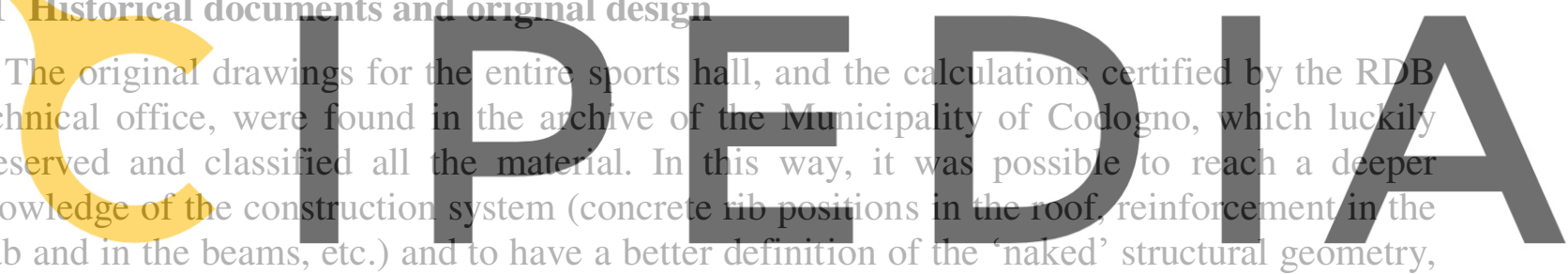

slab and in the beams, etc.) and to have a bett

Register for free at https//www.scipedia.com to download the version without the watermark

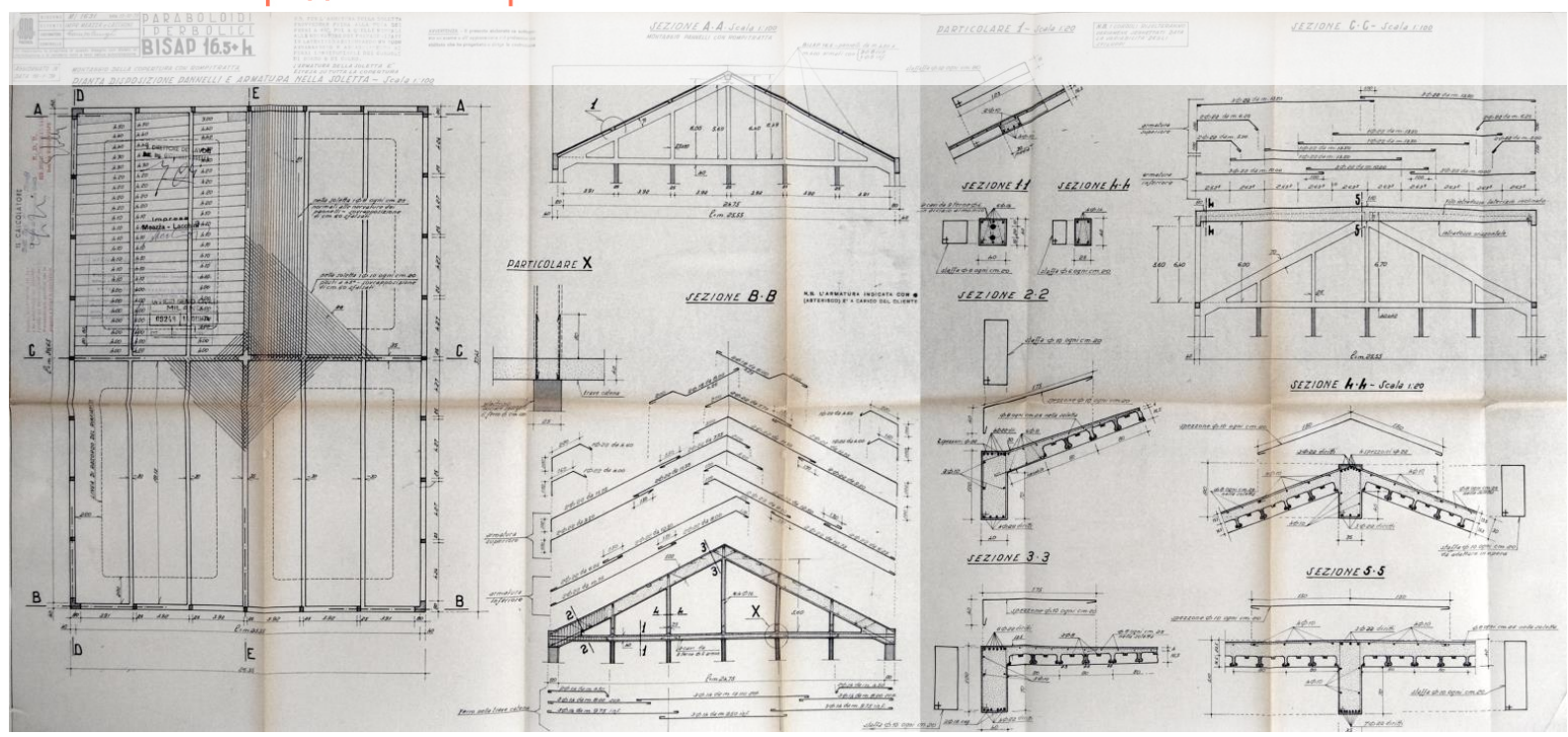

Figure 9. Example of the original drawings for the roof structure and the head gable. 


\section{STRUCTURAL ANALYSIS}

\subsection{The in-situ diagnosis campaign}

A preliminary in-situ campaign was disposed to control the possible state of decay of the concrete and the reinforcement, in order to avoid an over-estimation of structure resources. In particular, $\mathrm{n}^{\circ} 8$ concrete cylindrical specimen (100 mm diameter) were extracted from columns and walls and tested in laboratory. The results were compared with the 16 in-situ test performed combining ultrasonic velocity and rebound index. The concrete covering of steel reinforcement was measured in 10 positions, and the concrete cylinders were used to measure the depth of carbonation. P\&P Consulting Engineers, from Bergamo, made the tests.

\subsection{The seismic assessment}

A finite element model of the entire structure was set up, allowing to detect the overall behavior under static dead and live loads according to Italian Code (NTC18, [11]): it must be stressed that the actual loading provisions are far different from those adopted in the design in 1974. Moreover, the building structure was not at all designed for seismic loads, because only in recent years the territory of Codogno was classified in $3^{\text {rd }}$ category (seismicity of moderate intensity), with a reference GPA (ground peak acceleration) of $0.092 \mathrm{~g}$. That posed important questions on the possible strengthening intervention needed, because the building is open to the public and can have moderate crowding: allowing to NTC18, the building belongs to the Usage

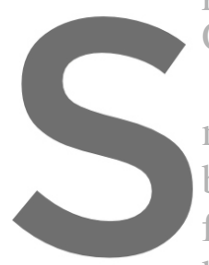
Class III, and the resultii

The model was set up ur nodes plate elements for beams. The concrete ribs too were modeled by from the surface, with a
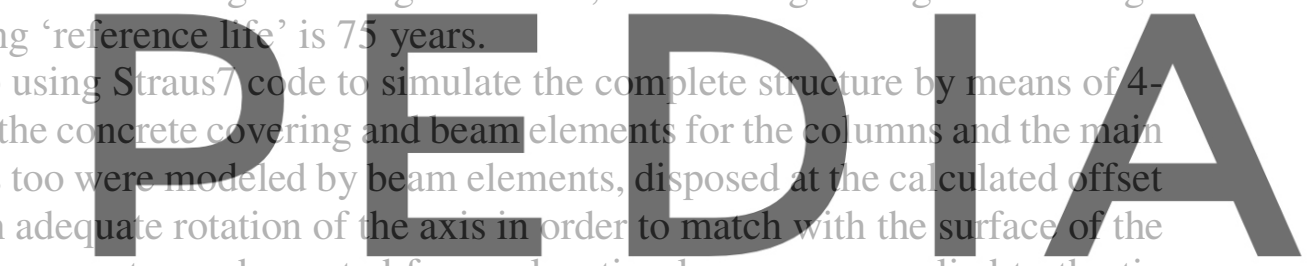

hypar. Finally, the design pre-stress, depurated from relaxation losses, was applied to the tie

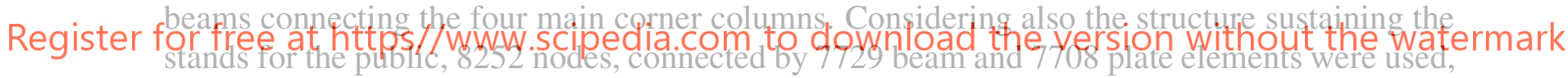
producing 49180 equations. The seismic analysis has been conducted with a linear elastic approach: first of all a modal dynamic analysis was performed that allowed detecting the main aspects of structural behavior.
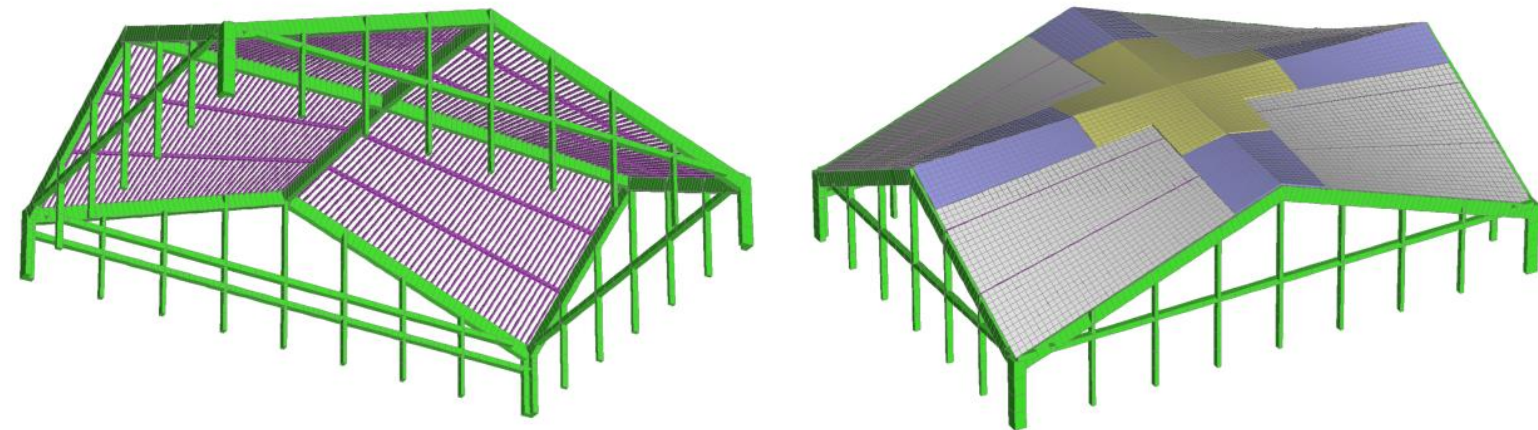

Figure 10. The Straus7 FE model: view from below (with the two cross beams) on the left, and view from the top on the right, different colors showing different shell thickness. 
The first three modes excite the structure in the three principal axis's directions, the lower being $2.456 \mathrm{~Hz}$ in $x$ (transversal) direction, and a torsional mode appear only at $6^{\text {th }}$ place, for higher frequency values $(5.032 \mathrm{~Hz}$, see Table 1 and Figs. 11 and 12). The presence of the walls supporting the gallery increase the horizontal stiffness of one long side, altering slightly the symmetry of the response (see mode 2 in Fig. 11 and mode 6 in Fig. 12).

Table 1: Mode participation for translational/rotational excitation

\begin{tabular}{|c|c|c|c|c|c|c|c|}
\hline Mode & Frequency & Modal Mass & Modal Stiff & $P F-X$ & $P F-Y$ & $P F-Z$ & $P F-R Z$ \\
\hline$\#$ & (Hz) & (Eng) & (Eng) & $(\%)$ & $(\%)$ & $(\%)$ & $(\%)$ \\
\hline $\mathbf{1}$ & $\mathbf{2 . 4 5 6 1}$ & $3.6934 \mathrm{E}+05$ & $8.7959 \mathrm{E}+07$ & $\mathbf{7 0 . 5 0 6}$ & 0.001 & 0.002 & 0.001 \\
\hline $\mathbf{2}$ & $\mathbf{3 . 3 7 3 0}$ & $1.4650 \mathrm{E}+05$ & $6.5802 \mathrm{E}+07$ & 0.001 & $\mathbf{5 7 . 0 5 5}$ & 0.000 & 3.642 \\
\hline $\mathbf{3}$ & $\mathbf{3 . 5 5 7 4}$ & $1.6221 \mathrm{E}+05$ & $8.1043 \mathrm{E}+07$ & 0.010 & 0.000 & $\mathbf{1 4 . 5 1 1}$ & 0.000 \\
\hline 4 & 4.2796 & $4.2821 \mathrm{E}+04$ & $3.0961 \mathrm{E}+07$ & 0.005 & 4.941 & 0.000 & 0.851 \\
\hline 5 & 4.5621 & $7.1018 \mathrm{E}+04$ & $5.8352 \mathrm{E}+07$ & 19.907 & 0.003 & 0.002 & 0.010 \\
\hline $\mathbf{6}$ & $\mathbf{5 . 0 3 1 9}$ & $6.8103 \mathrm{E}+04$ & $6.8076 \mathrm{E}+07$ & 0.011 & 0.794 & 0.000 & $\mathbf{4 6 . 2 4 8}$ \\
\hline 7 & 5.4197 & $4.9470 \mathrm{E}+04$ & $5.7366 \mathrm{E}+07$ & 0.000 & 1.716 & 0.000 & 7.445 \\
\hline 8 & 5.8253 & $3.1811 \mathrm{E}+04$ & $4.2616 \mathrm{E}+07$ & 0.001 & 9.851 & 0.000 & 1.553 \\
\hline 9 & 6.4518 & $6.2159 \mathrm{E}+04$ & $1.0215 \mathrm{E}+08$ & 0.001 & 0.000 & 0.043 & 0.000 \\
\hline 10 & 6.6768 & $5.4822 \mathrm{E}+04$ & $9.6484 \mathrm{E}+07$ & 2.290 & 0.014 & 10.701 & 0.085 \\
\hline 11 & 6.7630 & $5.7535 \mathrm{E}+04$ & $1.0389 \mathrm{E}+08$ & 0.002 & 7.712 & 0.055 & 28.280 \\
\hline 12 & 7.1368 & $6.5475 \mathrm{E}+04$ & $1.3165 \mathrm{E}+08$ & 3.284 & 0.010 & 2.669 & 0.014 \\
\hline 13 & 7.3690 & $3.4617 \mathrm{E}+04$ & $7.4212 \mathrm{E}+07$ & 0.032 & 0.000 & 14.731 & 0.001 \\
\hline
\end{tabular}
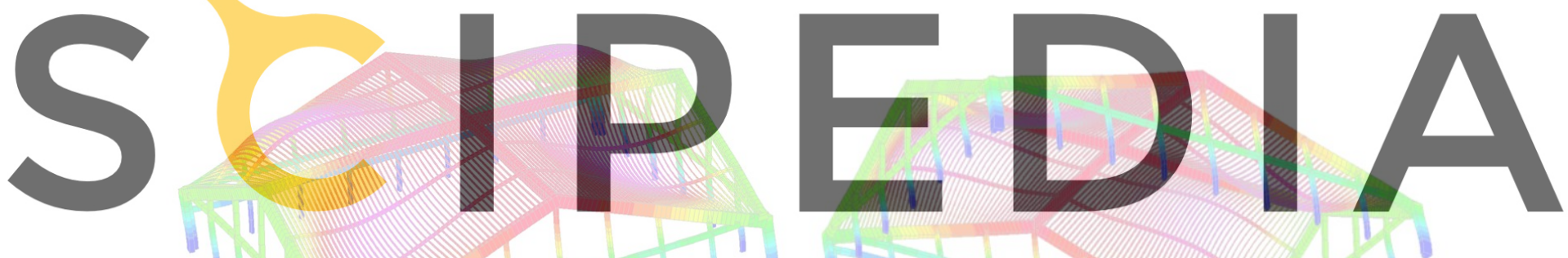

Register for free at https//www.scipedia.com to download the version without the watermark
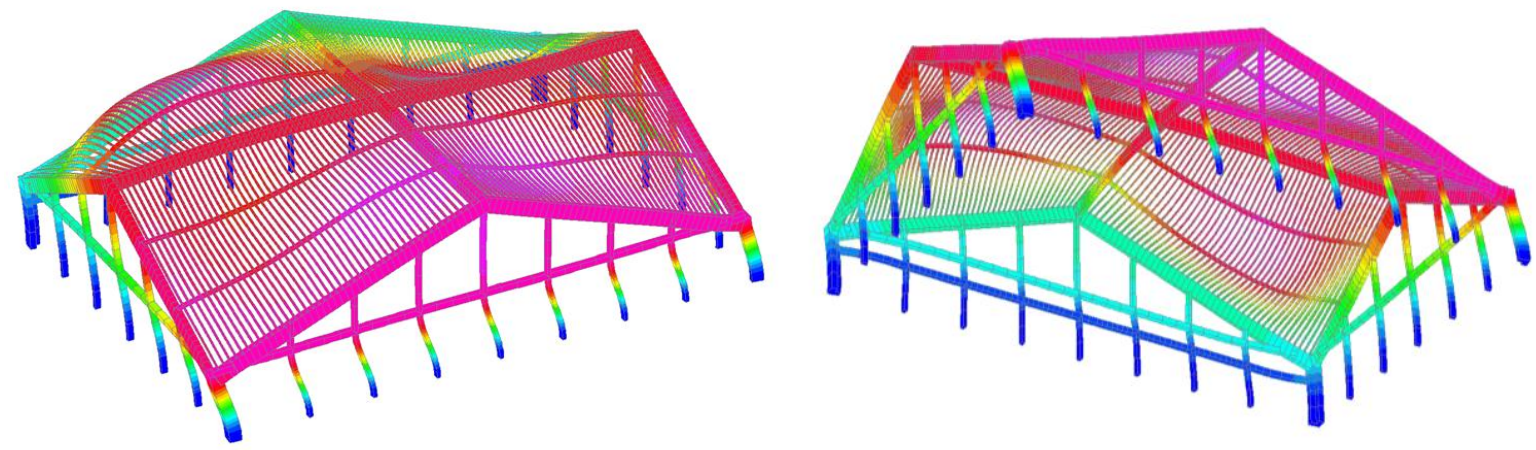

Figure 11. Mode 1 and 2 (flexural) shapes, Top: mode 1 horizontal displacement $D X$; bottom, mode 2 horizontal displacement $D Y$. Colored contour levels, view from top (left) and from below (right). 

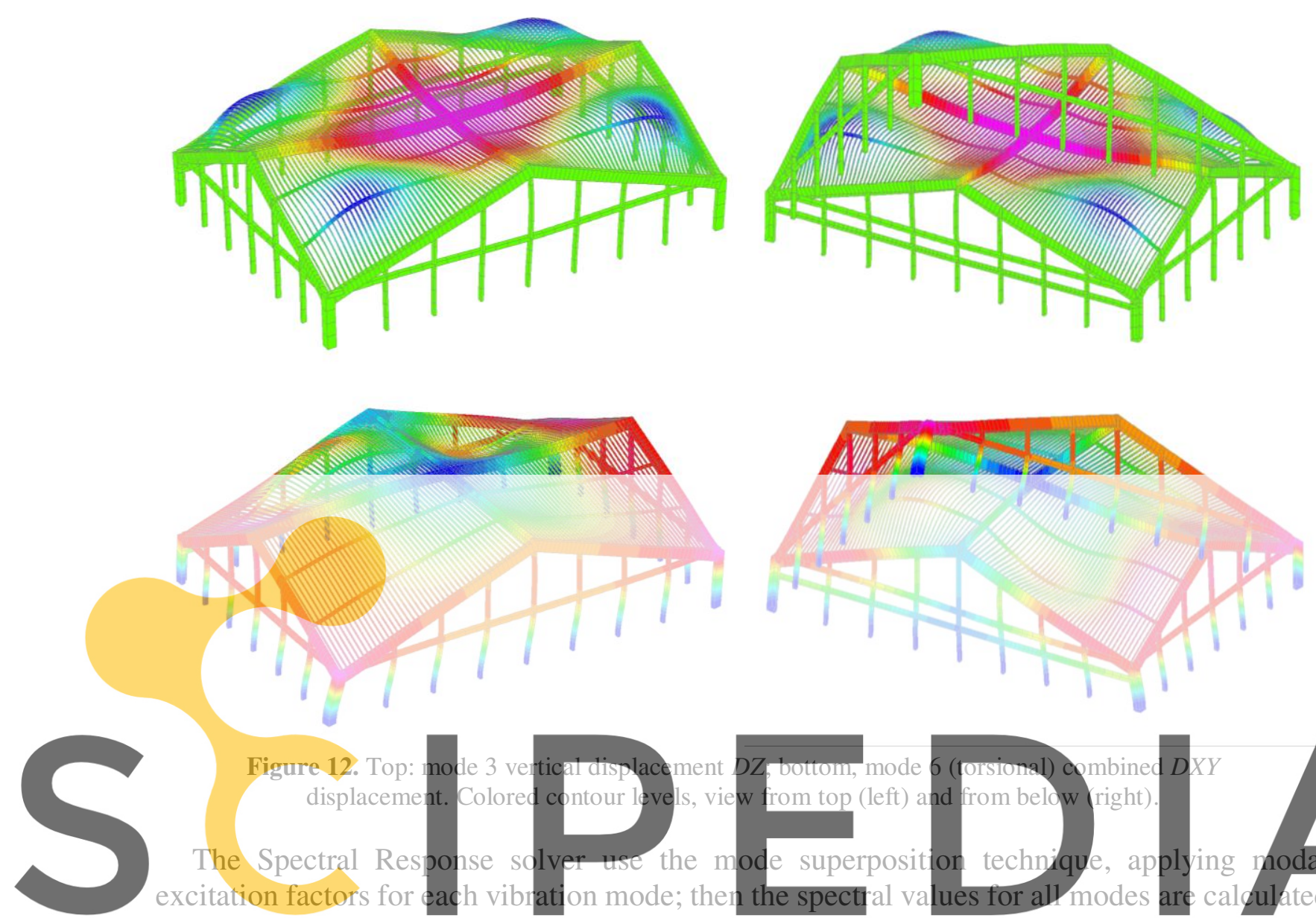

Figure 12. Top: mode 3 verticat displacement
displacement. Colored contour levels, vie

The Spectral Response solver use the m
citation factors for each vibration mode; then
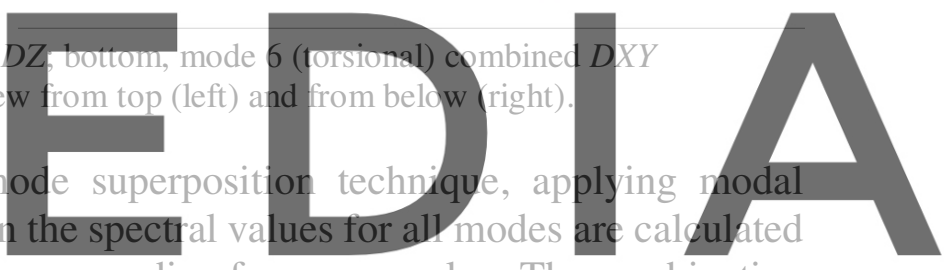

from the assigned spectral table by using the corresponding frequency value. The combination

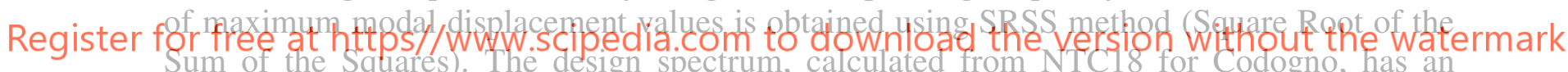
amplitude of $a_{0} S=0.138 \mathrm{~g}$.

The calculated stresses are then input in a verification program that check the capability of each structural member: the procedure is repeated reducing spectral amplification until the check is positive for all the members. A partial security coefficient take into account the 'level of knowledge' (LC) of materials and geometry obtained by visual and material inspections: LC2 was assumed, obtaining a factor of confidence of 1.2.

The more engaged members appeare to be the L-shaped corner columns, together with the closer slender columns that reach the gables; even the lower end of the rafters reach the limit state. The maximum capacity is attained with a spectral amplification of only $a_{g} S=0.08 \mathrm{~g}$, that leads to a ratio between capacity and demand:

$$
\zeta_{E}=0.080 \mathrm{~g} / 0.138 \mathrm{~g}=0.58
$$

Nevertheless, it must be stressed that Italian Code request for existing buildings in Usage Class III a minimum value of $\zeta_{E} \geq 0.6$ to be reached in an 'improvement intervention' (see $\S$ 8.4.2 of NTC18, [11]). 


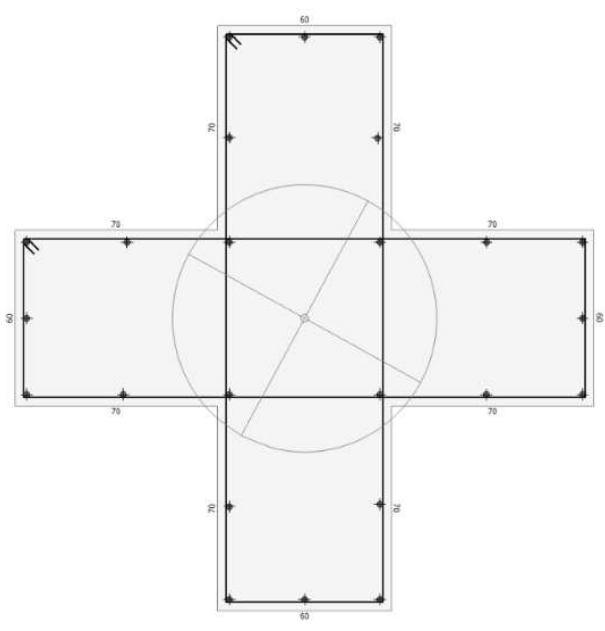

Figure 13. Enlarged cross section of corner columns

\subsection{The strengthening design}

In order to reach a satisfying capacity of the structure and reduce the vulnerability, the intervention chosen try to focus on the main weakness outlined by the calculations: the deformations and the shear resistance are concentrated in the corner columns.

Therefore, their section was increased changing from an L to an enlarged cross section (see Fig. 13), with an important change in stiffness. In this way, deformation amplitude was strongly reduced, and the structure results verified for the design spectrum amplitude forecast by the code, obtaining moreover a value of $\zeta_{E}=1.01 \geq 1$, that means a complete 'upgrade intervention', in the sense of $\S 8.4 .3$ of NT18 [11].

\section{CONCLUSIONS}

The structure of the Codogno Sports Hall demonstrated to be still very effective, and is very close to satisfying code requirements even in present conditions. Nevertheless, with a moderate upgrade only on the corner columns, it is able to reach a complete compliance to code provision for new buildings towards seismic assessment, showing the clever vision of the original design that worth some minor conservation interventions.

Acknowledgements. The administration of Codogno Municipality and the staff of historical archive is gratefully acknowledged for the cooperation in the research of original drawings; eng. Guido Campana, from Campana \& Migliorin, is acknowledged for structural verifications.

\section{REFERENCES}

[1] Sprague, T.S. 'Beauty, Versatility, Practicality': the Rise of Hyperbolic Paraboloids in PostWar America (1950-1962). Construction History, vol. 28, no. 1, pp. 165-184, (2013). JSTOR, http://www.jstor.org/stable/43856033.

[2] Engel, H. Structure Systems. (1968) London: Iliffe books.

[3] Journal of the International Association for Shell and Spatial Structures n. 163, Special Issue for the Centenary of the Birth of Félix Candela, Vol. 51 (2010) No. 1 March

[4] Burger, N. and Billington, D.P.: Felix Candela, elegance and endurance: an examination of the Xochimilco shell, Journal of the International Association for Shell and Spatial Structures, Vol. 47 (2006) No. 3 December n. 152, pp. 271-278(8).

[5] Modica, M. and Santarella, F.: Paraboloidi: un patrimonio dimenticato dell'architettura moderna. Firenze, Edifir (2014).

[6] Paolini C. and Pugnaletto, M.: Reinforced brick lightweight vaults. TEMA, vol. 3, No. 1 (2017).

[7] IL, Il Laterizio, bollettino tecnico RDB, RDB, Piacenza (1961) n. 70 e 71. 
[8] IL, Il Laterizio, bollettino tecnico RDB, RDB, Piacenza (1976) n. 158-159.

[9] Zienkiewicz, O.C. and Taylor, R.L. The finite element method. McGraw Hill, Vol. I., (1989), Vol. II, (1991).

[10] Straus7, Theoretical Manual. Sydney Aus.: Strand7 Pty Limited, 2005.

[11] D.M. 17.01.2018 - Norme tecniche per le costruzioni, Supplemento ordinario alla Gazzetta Ufficiale n. 42 del 20 febbraio 2018 - Serie generale (2018).

[12] Circolare n.7 del 21.01.2019 Istruzioni per l'applicazione dell'Aggiornamento delle «Norme tecniche per le costruzioni» di cui al D.M 17 gennaio 2018. S.O. alla Gazzetta Ufficiale n.35 del 11 febbraio 2019 - Serie generale (2019). 